\title{
High-Fidelity Transmission Acquired via a Developmental Decrease in NMDA Receptor Expression at an Auditory Synapse
}

\author{
Kensuke Futai, Masayoshi Okada, Kyoko Matsuyama, and Tomoyuki Takahashi \\ Department of Neurophysiology, University of Tokyo Faculty of Medicine, Tokyo 113-0033, Japan
}

Central auditory relay synapses in mature animals follow highfrequency inputs for computation of sound localization. In immature mice, however, transmission at the calyx of Held synapse in auditory brainstem was inaccurate for high-frequency inputs because the summed slow synaptic potential components caused aberrant firings or blocked action potentials. As the mice matured, synaptic potentials became shorter, with smaller and faster NMDA receptor components, thereby establishing the precise one-to-one transmission for high-frequency inputs. Developmental acquisition of this high-fidelity transmission could be mimicked experimentally in immature mice by blocking NMDA receptors with $\mathrm{D}(-)$ 2-amino-5-phosphonovaleric acid (D-APV). Furthermore, bilateral cochlear ablations at postnatal day 7 (P7) attenuated the developmental decrease of NMDA receptor expression and prevented the acquisition of high-fidelity transmission. We suggest that auditory activity, which begins at P10-P12 in mice, downregulates the expression of postsynaptic NMDA receptors, thereby contributing to the establishment of high-fidelity synaptic transmission.

Key words: NMDA receptor; high-fidelity synaptic transmission; postnatal development; the calyx of Held; cochlear ablation; excitatory postsynaptic current; AMPA receptor
In the mammalian auditory system, sound localization is achieved via the comparison of the timing and strength of sound detected at each cochlea (Oertel, 1997; Trussell, 1997). The principal cell in the medial nucleus of the trapezoid body (MNTB) is a glycinergic inhibitory neuron that receives a single excitatory glutamatergic input from a contralateral globular bushy cell in anterior ventral cochlear nucleus. The giant nerve terminal called the calyx of Held forms an axo-somatic synapse on the MNTB principal neuron (Held, 1893). The MNTB neurons send projections to the lateral superior olivary neurons, which also receive excitatory inputs from ipsilateral cochlear neurons, allowing the sound intensities from each cochlea to be compared. Such temporal cues rely on a high-fidelity synaptic transmission along the auditory pathway.

The calyx of Held synapse is formed at P4-P6 but undergoes developmental changes during the second postnatal week, when the animals begin to detect sound (Mikaelian and Ruben, 1964; Kikuchi and Hilding, 1965). During this period the nerve terminal is reformed from "spoon-shaped" to "finger-like" via "fenestration" (Kandler and Friauf, 1993), and presynaptic $\mathrm{Ca}^{2+}$ channels switch from a mixture of $\mathrm{N}, \mathrm{P} / \mathrm{Q}$, and $\mathrm{R}$ types to the $\mathrm{P} / \mathrm{Q}$ type (Iwasaki and Takahashi, 1998). We report here that during this period the synaptic transmission acquires fidelity for highfrequency inputs mainly via an auditory activity-dependent downregulation of postsynaptic NMDA receptor expression.

\footnotetext{
Received Dec. 27, 2000; revised Feb. 14, 2001; accepted Feb. 27, 2001.

This study was supported by the Research for the Future Program of The Japan Society for the Promotion of Science. We thank Katsunori Kobayashi, David Saffen, and Tetsuhiro Tsujimoto for discussion and comments on this manuscript. We are also grateful to Masayoshi Mishina and Hisashi Mori for providing us with anti- $\epsilon$ subunit antibodies and to Yasuhiro Kakazu and Junichi Nabekura for technical instructions on cochlear ablation.

K.F. and M.O. contributed equally to this work.

Correspondence should be addressed to Tomoyuki Takahashi, Department of Neurophysiology, University of Tokyo Faculty of Medicine, Tokyo 113-0033, Japan. E-mail: ttakahas-tky@umin.u-tokyo.ac.jp.

Copyright (C) 2001 Society for Neuroscience $0270-6474 / 01 / 213342-08 \$ 15.00 / 0$
}

\section{MATERIALS AND METHODS}

Electrophysiology. All experiments were performed in accordance with the guidelines of the Physiological Society of Japan. Transverse brainstem slices (200-250 $\mu \mathrm{m}$ thick) containing the MNTB were prepared from 5- to 7-d-old C57BL mice that were decapitated under halothane anesthesia (Forsythe and Barnes-Davies, 1993). Slices were incubated for $30 \mathrm{~min}$ at $37^{\circ} \mathrm{C}$ and maintained at room temperature. The extracellular artificial CSF (aCSF) for perfusion contained (in mM): $120 \mathrm{NaCl}, 2.5$ $\mathrm{KCl}, 26 \mathrm{NaHCO}_{3}, 1.25 \mathrm{NaH}_{2} \mathrm{PO}_{4}, 2 \mathrm{CaCl}_{2}, 1 \mathrm{MgCl}_{2}, 10$ D-glucose, 3 myo-inositol, 2 sodium pyruvate, and 0.5 ascorbate, $\mathrm{pH}$-adjusted to 7.4 when saturated with $5 \% \quad \mathrm{CO}_{2}$ and $95 \% \mathrm{O}_{2}$. For electrophysiological recordings the slices were mounted on an upright microscope (BX50W I, Olympus, Tokyo, Japan), and MNTB principal neurons were identified visually with an infrared (IR) differential interference contrast video microscopy attached with an IR-CCD camera (Hamamatsu Photonics, Ichinocho, Japan). The patch pipette solution for voltage-clamp recordings contained (in $\mathrm{mm}$ ): 115 Cs-gluconate, $20 \mathrm{CsCl}, 10 \mathrm{HEPES}, 0.5$ EGTA, 10 phosphocreatine, 4 ATP, and $0.3 \mathrm{GTP}$, pH-adjusted to 7.3 with $\mathrm{CsOH}$. To suppress action potential generation, we included $N-(2,6-$ dimethylphenylcarbamoylmethyl) triethylammonium chloride (QX314; 5 $\mathrm{mm}$, Alomone Labs, Jerusalem, Israel) in the pipette solution.

For current-clamp recordings the cesium was replaced by potassium and QX314 was omitted. Recording pipettes were made of thick-walled borosilicate glass pipettes (Clark Electrochemical, Pangbourne, UK) pulled to the resistance of 2-3 M $\Omega$. Whole-cell recordings were made with an Axopatch 200B amplifier (Axon Instruments, Foster City, CA). In voltage-clamp experiments the series resistance was typically $10-15$ $\mathrm{M} \Omega$ and compensated by $>85 \%$. Membrane potentials were corrected for a liquid junction potential $(-9 \mathrm{mV})$ between the extracellular and pipette solutions. All experiments were performed at $26-27^{\circ} \mathrm{C}$, using a bath temperature controller (DTC-200, DIA Medical System). Postsynaptic responses were evoked in MNTB principal neurons at $0.1 \mathrm{~Hz}$, using a bipolar tungsten electrode positioned half-way between the midline of the slice and the MNTB (Forsythe and Barnes-Davies, 1993). Before a gigaohm seal was formed, principal neurons receiving an excitatory input were identified from orthodromic spikes recorded extracellularly from a patch pipette. EPSCs evoked in an all-or-none manner for a graded stimulus intensity and having amplitudes $>1 \mathrm{nA}$ at $-79 \mathrm{mV}$ were selected as those derived from the calyx of Held (Forsythe and BarnesDavies, 1993). To isolate NMDA-EPSCs, we added 6-cyano-7nitroquinoxaline-2,3-dione (CNQX; $20 \mu \mathrm{M}$; Tocris, Bristol, UK) or GYKI 52466 (100 $\mu \mathrm{M}$; Research Biochemicals, Natick, MA) to the bath solution, and neurons were voltage-clamped at $+51 \mathrm{mV}$. The aCSF 


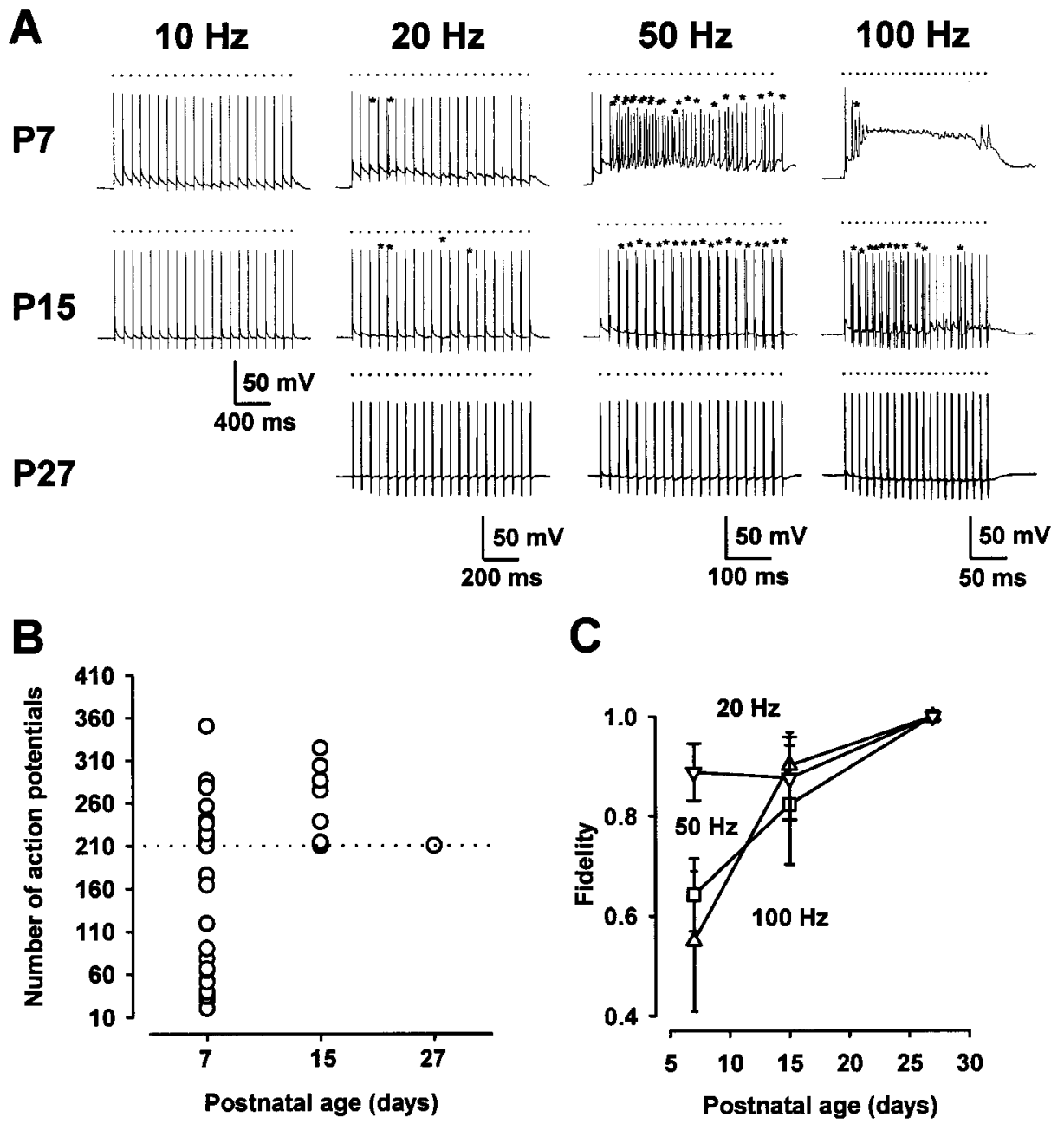

Figure 1. Postnatal development of highfidelity synaptic transmission. $A$, Postsynaptic responses evoked by a train of high-frequency stimuli (21 pulses at $10,20,50$, or $100 \mathrm{~Hz}$ ) in mice at different postnatal periods (P7, P15, P27). Dots and asterisks indicate the timing of stimuli and aberrant action potentials, respectively, in this figure and in Figure 3. Resting potentials were $-71 \mathrm{mV}(\mathrm{P} 7),-69 \mathrm{mV}(\mathrm{P} 15)$, and $-72 \mathrm{mV}$ (P27), respectively. $B$, Number of postsynaptic action potentials for 210 stimuli at $100 \mathrm{~Hz}$ at different postnatal periods. Of 27 cells, 16 cells showed a block and 8 cells showed aberrant firings at P7. Aberrant firings were found in 8 of 17 cells at P15 and none in 10 cells at P27. C, Developmental increase in the fidelity of transmission. "Fidelity" in the ordinate is defined as $\left(210-n_{\mathrm{a}}\right) / 210$, where $n_{\mathrm{a}}$ represents the number of aberrant spikes during 210 stimuli (for details, see Materials and Methods). Data points and error bars in this and the following figures indicate means \pm SEM. Each data point was derived from 8-27 cells. In P7 mice the data of action potential block are excluded from this plot. routinely contained $100 \mu \mathrm{M}$ picrotoxin (Wako, Osaka, Japan) and $0.5 \mu \mathrm{M}$ strychnine (Sigma, St. Louis, MO) to block inhibitory synaptic responses.

Records were filtered at $5 \mathrm{kHz}$ and sampled at $10 \mathrm{kHz}$ by an LM-12 interface (Dagan, Minneapolis, MN). The fidelity of synaptic transmission was evaluated from the number of aberrant action potentials $\left(n_{\mathrm{a}}\right)$ during 10 trains each, comprising 21 stimuli and expressed as (210$\left.n_{\mathrm{a}}\right) / 210$. Postsynaptic responses having a half-width $>2 \mathrm{msec}$ were not counted into action potentials. Values in the text and figures are given as means \pm SEM; the significance of difference was evaluated by Welch's test or paired $t$ test.

Biochemistry. Messenger RNAs encoding NMDA receptor subunits were measured by the reverse transcription-PCR (RT-PCR) method. Tissues including the MNTB regions were trimmed from transverse brainstem slices from five mice each at different postnatal ages, and total RNA was extracted by using the acid guanidine phenol chloroform method. The cDNAs were synthesized by using SuperScript II (Life Technologies, Gaithersburg, MD) and random hexamers as primers. Then the RT products were amplified by PCR with Taq DNA polymerase (Promega, Madison, WI). The subunit cDNAs were amplified with primers specific to the $\zeta 1$ subunit (Mizuta et al., 1998) and primers common to the $\epsilon 1$ and $\epsilon 2$ subunits (Sakaguchi et al., 1997). The PCR primers used for the $\zeta 1$ subunit were CTGGTGCTGGATAGGCCTGA and GCTGCATCTGCTTCCTACGG, and those for the $\epsilon 1 / 2$ subunits were GTGATGCTGCTCATTGTCTCTGC and CAGATGAAGGTGATGAGGCTGAG. The primer for glyceraldehyde-3-phosphate dehydrogenase $(\mathrm{G} 3 \mathrm{PDH})$ was purchased from Clontech (Palo Alto, CA). The PCR program was as follows: (1) the initial denaturation at $95^{\circ} \mathrm{C}$ for 5 min; (2) 20 cycles of $95^{\circ} \mathrm{C}$ for $50 \mathrm{sec}, 63^{\circ} \mathrm{C}$ for $50 \mathrm{sec}$, and $72^{\circ} \mathrm{C}$ for $50 \mathrm{sec}$ for $\zeta 1,25$ cycles for $\epsilon 1 / 2$, and 18 cycles for G3PDH; (3) the final elongation at $72^{\circ} \mathrm{C}$ for $5 \mathrm{~min}$. To ensure the specificity of this PCR method, we subcloned PCR products into pCR2.1 plasmid and subsequently sequenced them. Randomly sampled clones $(\zeta 1, \epsilon 1 / 2 ; n=22$ and
20 , respectively) contained only $\zeta 1$ and $\epsilon 1 / 2$ subunit DNAs. Plasmids were prepared with Qiagen plasmid kits (Hilden, Germany). To measure the amount of subunit mRNA, we performed PCR amplification in the presence of ${ }^{32} \mathrm{P}$-radiolabeled dCTP $(1.48 \mathrm{MBq} / \mathrm{ml})$, followed by acrylamide gel electrophoresis and quantification with a BAS2000 image analyzer (Fuji Film, Tokyo, Japan). In cochlear ablation experiments, mRNAs were quantified with FluoroImager 595 (Molecular Dynamics, Sunnyvale, CA) after the gels were stained with SYBR GreenI (Molecular Probes, Eugene, OR). In these experiments PCR cycles were 20 for $\zeta 1,26$ for $\epsilon$, and 19 for G3PDH.

The amount of NMDA receptor subunit protein expressed in the MNTB region was examined at different postnatal ages by immunoblotting. The tissues trimmed for the MNTB regions from brainstem slices of 10 mice were pooled and homogenized with $50 \mathrm{~mm}$ Tris- $\mathrm{HCl}, \mathrm{pH} 8.0$, $150 \mathrm{~mm} \mathrm{NaCl}, 1 \% \mathrm{NP}-40,2 \mathrm{~mm}$ EDTA, $2 \mu \mathrm{g} / \mathrm{ml}$ leupeptin, and $2 \mu \mathrm{g} / \mathrm{ml}$ pepstatin A. The homogenates were fractionated on an SDSpolyacrylamide gel $(6 \%)$, electroblotted onto Immobilon-P membrane (Millipore, Bedford, MA), and reacted with an anti- $\zeta 1$ subunit antibody (Chemicon, Temecula, CA) or with anti- $\epsilon 1$ or anti- $\epsilon 2$ subunit antibodies (generous gift from Drs. Mishina and Mori, University of Tokyo, Japan). The antibodies were visualized with a secondary antibody labeled with HRP (Promega) and an ECL Western detection kit (Amersham Japan, Tokyo, Japan). The amount of receptors was quantified with a densitometer (GS-700, Bio-Rad, Hercules, CA).

Cochlear ablation. Bilateral cochlear ablation was made at P7. Mice were anesthetized with diethyl ether, and an incision was made just behind the pinna. Under a dissecting microscope the middle ear cavity was exposed and the bony wall of the cochlea was identified. Then the cochlea was destroyed carefully by using a needle. In control shamoperated mice only incisions behind the pinna were made. After suturing the incision, we placed the animals on a heating pad. After recovery from anesthesia the pups were returned to the original cage and reared until 
A

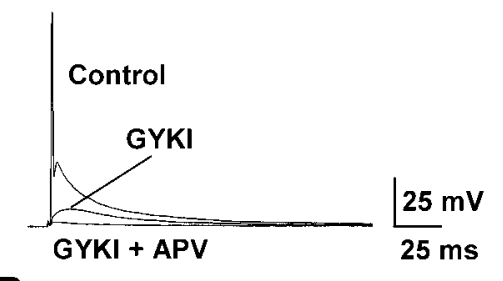

B

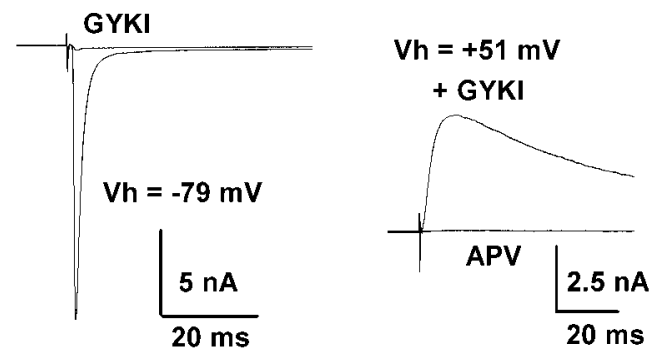

Figure 2. Pharmacological properties of EPSPs and EPSCs recorded from MNTB neurons. $A$, Action potentials triggered by EPSPs elicited by extracellular stimulation of an MNTB principal neuron at P7. GYKI $52466(100 \mu \mathrm{M})$ abolished action potentials but did not block the slow EPSP component. This component was abolished by the additional application of D-APV $(50 \mu \mathrm{M})$. Averaged records before (Control) and during applications of GYKI and GYKI + D-APV are superimposed. The resting potential was $-67 \mathrm{mV}$. B, Left, EPSCs evoked at the holding potential of $-79 \mathrm{mV}$ under voltage clamp in another MNTB neuron at P7. EPSCs were blocked by GYKI $52466(100 \mu \mathrm{M}$; before and after GYKI records are superimposed). Right, In the presence of GYKI, EPSCs appeared as outward current at the holding potential of $+51 \mathrm{mV}$. These EPSCs were abolished by D-APV (50 $\mu \mathrm{M}$; superimposed).

$\mathrm{P} 13$. At $\mathrm{P} 13$ the auditory brainstem response (ABR) was measured under pentobarbital anesthesia by using four subcutaneous electrodes: two electrodes inserted under both ears, one at the top of skull, and a ground electrode inserted under the back. A $5 \mathrm{kHz}$ click sound (duration, $1 \mathrm{msec}$ ) of $85 \mathrm{~dB}$ in intensity was given to the mice through an earphone. The sound intensity through the earphone was calibrated by a sound pressure meter (NL-04, Rion). The ABR was amplified and averaged with bioamplifier DAM80 (World Precision Instruments, Everett, WA) and pClamp 8 (Axon Instruments). Control and test mice were derived from the same litter.

\section{RESULTS}

\section{Maturation of high-fidelity transmission at the calyx of} Held synapse

We recorded EPSPs associated with action potentials from a principal neuron in the MNTB in P7 mice after the extracellular stimulation of presynaptic bushy cell axons. When the stimulation frequency was lower than $10 \mathrm{~Hz}$, postsynaptic cells fired in response to inputs in a one-to-one manner (Fig. $1 \mathrm{~A}$, at $26-27^{\circ} \mathrm{C}$ ). However, at a frequency higher than $20 \mathrm{~Hz}$, depolarization caused by summed tails of EPSPs triggered aberrant firings. At $100 \mathrm{~Hz}$, in a subset of cells in P7 mice, action potentials eventually were blocked (Fig. 1A,B), as reported at the same synapse in $\mathrm{P} 6$ rats (Taschenberger and Gersdorff, 2000). Thus synaptic transmission at high frequency was inaccurate in P7 mice. In P15 mice, however, transmission was more precise, with fewer aberrant firings, and action potentials no longer were blocked during 100 $\mathrm{Hz}$ stimulation (Fig. 1A,B; see also Taschenberger and Gersdorff, 2000). At P27, neither the aberrant firing nor the block was observed at $100 \mathrm{~Hz}$ (Fig. $1 B$ ) or at a higher frequency up to 400 $\mathrm{Hz}$ (data not shown). The fidelity of transmission evaluated from the number of aberrant firings (see Materials and Methods) was higher at a lower frequency of stimulation and in more mature animals for a given frequency of stimulation (Fig. 1C).

\section{Pharmacological characterization of synaptic responses}

To determine mechanisms underlying the development of highfidelity transmission, we first characterized the pharmacological properties of the postsynaptic responses. Application of the
Figure 3. Gain in fidelity of transmission by blocking NMDA receptors. $A$, Postsynaptic responses during a train of $100 \mathrm{~Hz}$ stimuli in MNTB neurons at different postnatal periods. In immature mice D-APV $(50 \mu \mathrm{M})$ abolished aberrant firings and relieved action potentials from block, thereby making synaptic transmission accurate. Resting potentials were $-69 \mathrm{mV}(\mathrm{P} 7),-72$ $\mathrm{mV}(\mathrm{P} 15)$, and $-67 \mathrm{mV}(\mathrm{P} 27) . B$, A similar effect of D-APV on postsynaptic responses at $35^{\circ} \mathrm{C}$ in a $\mathrm{P} 7$ mouse. Resting potential was $-66 \mathrm{mV}$. $C$, Summary of the effects of D-APV on the fidelity of transmission at $100 \mathrm{~Hz}(n=10-11)$ before $(\boldsymbol{\Delta})$ and after $(\triangle)$ D-APV application at $26-27^{\circ} \mathrm{C}$. D-APV had no effects on synaptic fidelity in P27 mice.

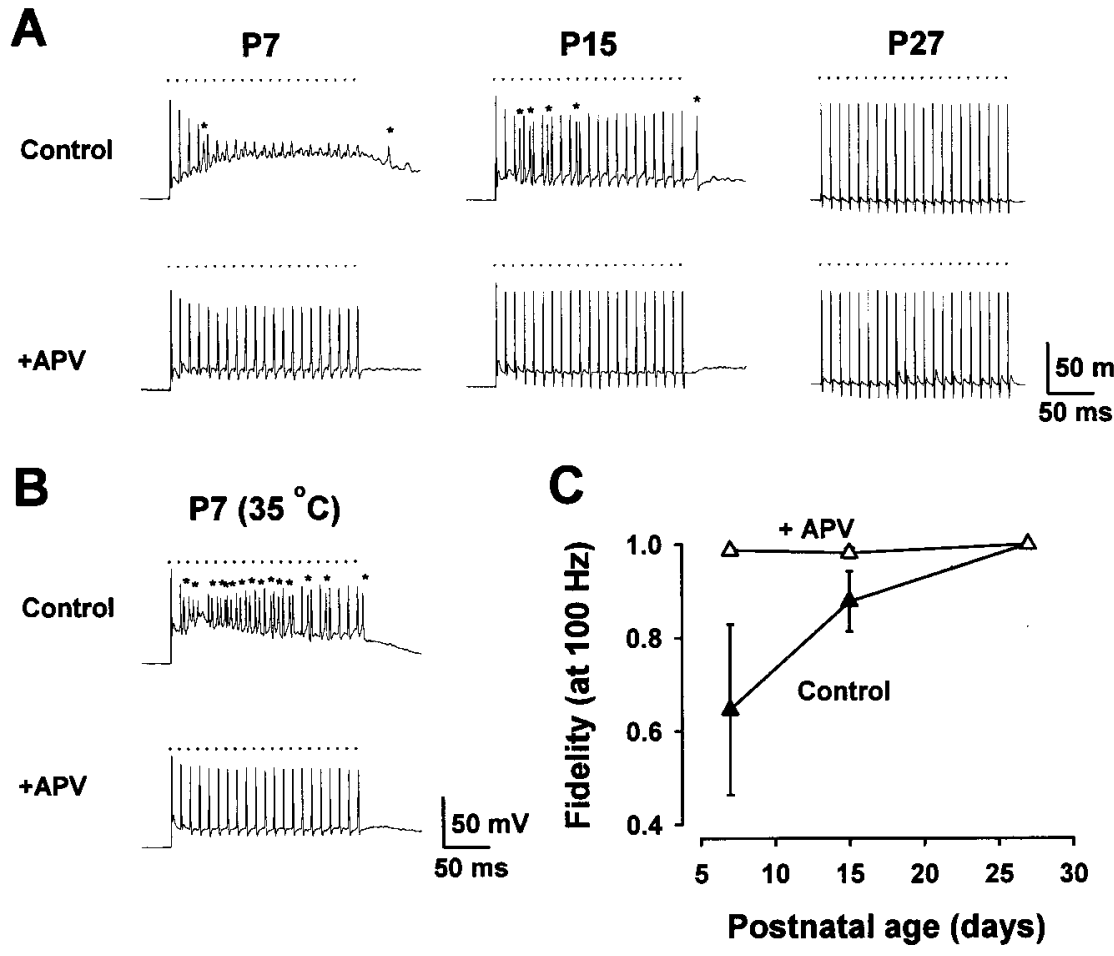




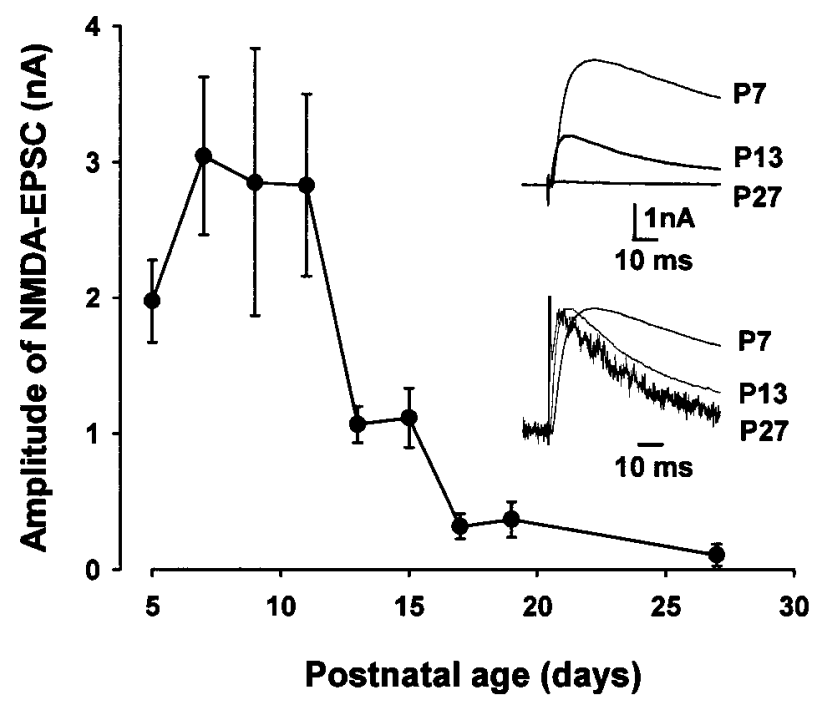

Figure 4. Developmental changes in NMDA-EPSCs. $A$, Developmental decrease in the mean amplitude of NMDA-EPSCs recorded at $+51 \mathrm{mV}$ holding potential in the presence of CNQX $(20 \mu \mathrm{M})$. Each data point was derived from 15-23 MNTB neurons. Sample traces are averaged NMDAEPSCs (10 events) in P7, P13, and P27 mice, superimposed (top column), and shown with their peak amplitudes normalized and aligned at the stimulus artifact (bottom column).

AMPA receptor antagonist GYKI $52466(100 \mu \mathrm{M})$ in large part suppressed EPSPs to levels below the action potential threshold, but a slow component remained unblocked (Fig. $2 A$ ). This component was abolished by the additional application of the NMDA receptor antagonist $\mathrm{D}(-)$ 2-amino-5-phosphonovaleric acid (DAPV; $50 \mu \mathrm{M})$. The effect of GYKI was reversible after wash out (data not shown). Under voltage clamp the AMPA and NMDA receptor components of EPSCs also were recorded in isolation (Fig. 2B). At a holding potential of $-79 \mathrm{mV}$, large EPSCs typical of those derived from the calyceal nerve terminal (Forsythe and Barnes-Davies, 1993) were recorded. These EPSCs were blocked almost completely ( $>99 \%)$ by GYKI (100 $\mu \mathrm{M}$; Fig. $2 B)$. Thus the excitatory transmission at this calyceal synapse is mediated by both AMPA and NMDA receptors, but to a much lesser extent by kainate receptors. Although the NMDA component of EPSCs was not detected at the holding potential of $-79 \mathrm{mV}$ in the presence of GYKI, presumably because of voltage-dependent $\mathrm{Mg}^{2+}$-block, it was revealed as an outward current at $+51 \mathrm{mV}$. These currents were abolished by D-APV $(50 \mu \mathrm{M})$, confirming that they were mediated by NMDA receptors.

\section{Negative contribution of NMDA receptors to high-fidelity transmission}

Because the duration of synaptic potentials is very short in mature animals, temporal summation occurs only over short times; therefore, the firing patterns of auditory nerve inputs are preserved (Oertel, 1997). In immature mice, however, aberrant firings and the block of action potentials occur as a result of the summed EPSPs. Given that the slow component of EPSPs is mediated by NMDA receptors (Fig. 2), we examined whether NMDA receptors might be responsible for the inaccurate transmission in immature mice. After bath application of D-APV $(50 \mu \mathrm{M}), 100 \mathrm{~Hz}$ stimulation no longer caused aberrant firings or blocked action potentials (Fig. 3A). Thus D-APV converted low-fidelity transmission in immature mice into high-fidelity transmission (Fig. $3 C$ ). In the presence of D-APV, however, EPSPs still summed to produce
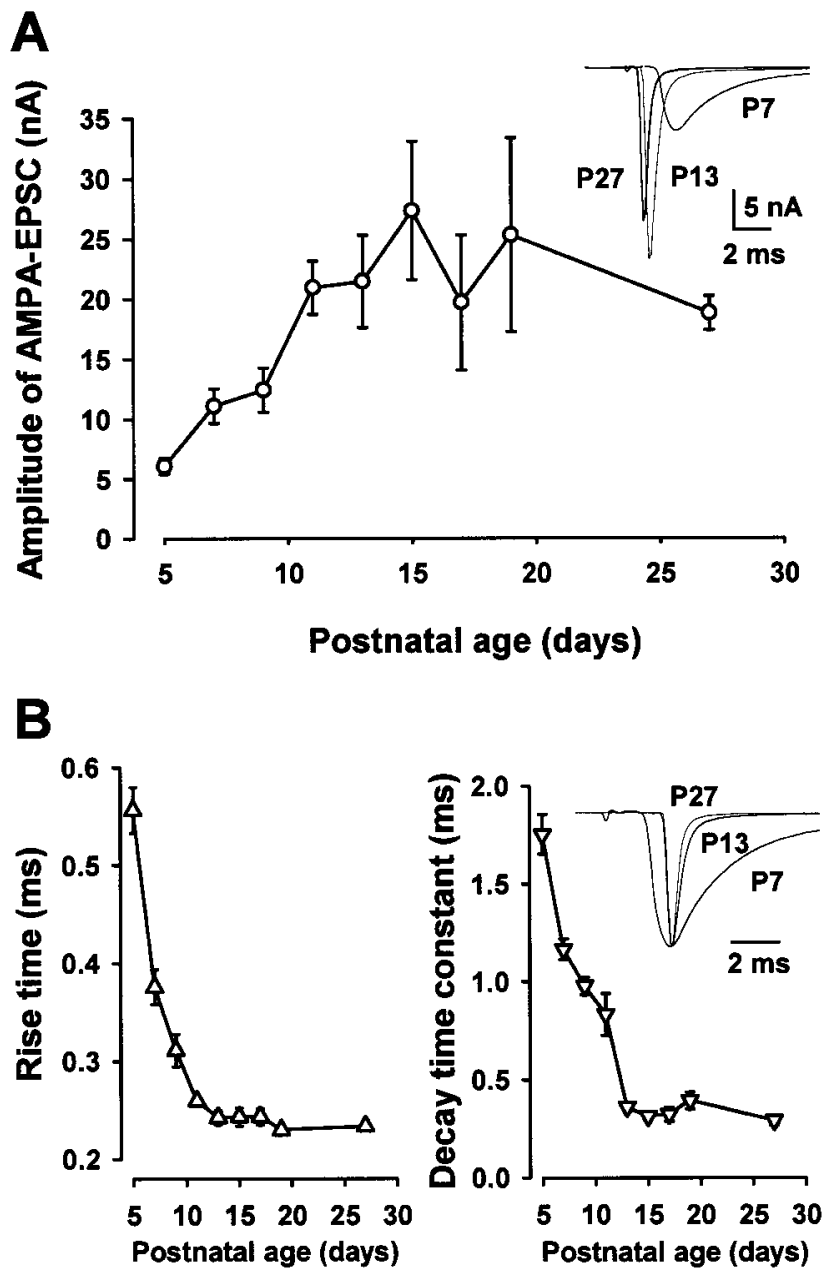

Figure 5. Developmental changes in AMPA-EPSCs. $A$, Developmental increase in the mean amplitude of AMPA-EPSCs recorded at $-79 \mathrm{mV}$ holding potential $(n=15-23)$. After EPSCs were recorded, CNQX (20 $\mu \mathrm{M})$ was applied, and the small CNQX-resistant component was subtracted for the data plotted in this graph. The superimposed sample traces are averaged EPSCs (10 events) at $-79 \mathrm{mV}$ holding potential in P7, P13, and P27 mice aligned at the stimulus artifact. Note that the synaptic latency is shorter at more mature mice. $B$, The $10-90 \%$ rise time and the decay time constant of AMPA-EPSCs at different postnatal age. The decay time could be fit adequately by a single exponential function for the data presented in the time plot. The superimposed sample traces are AMPA-EPSCs at P7, P13, and P27 normalized in amplitude and aligned at their peak.

a sustained depolarization in $\mathrm{P} 7$ and P15 mice, but not in P27 mice (Fig. 3A). During $200 \mathrm{~Hz}$ stimulation in $\mathrm{P} 7$ mice, this depolarization exceeded the action potential threshold and produced aberrant firings (data not shown). Thus, there seems to be a factor or factors in addition to NMDA receptors that can interfere with the fidelity of transmission.

We next examined whether the above results observed at $26-27^{\circ} \mathrm{C}$ were reproducible at a physiological temperature in $\mathrm{P} 7$ mice. At $35^{\circ} \mathrm{C}, 100 \mathrm{~Hz}$ stimulation induced many aberrant firings, but action potentials no longer were blocked (in all 13 cells that were examined), presumably because of faster kinetics of EPSPs at higher temperature (Fig. 3B). After the application of D-APV $(50 \mu \mathrm{M})$, aberrant firings were eliminated completely, resulting in accurate synaptic transmission as observed at $26-27^{\circ} \mathrm{C}$. Similar results also were obtained after 


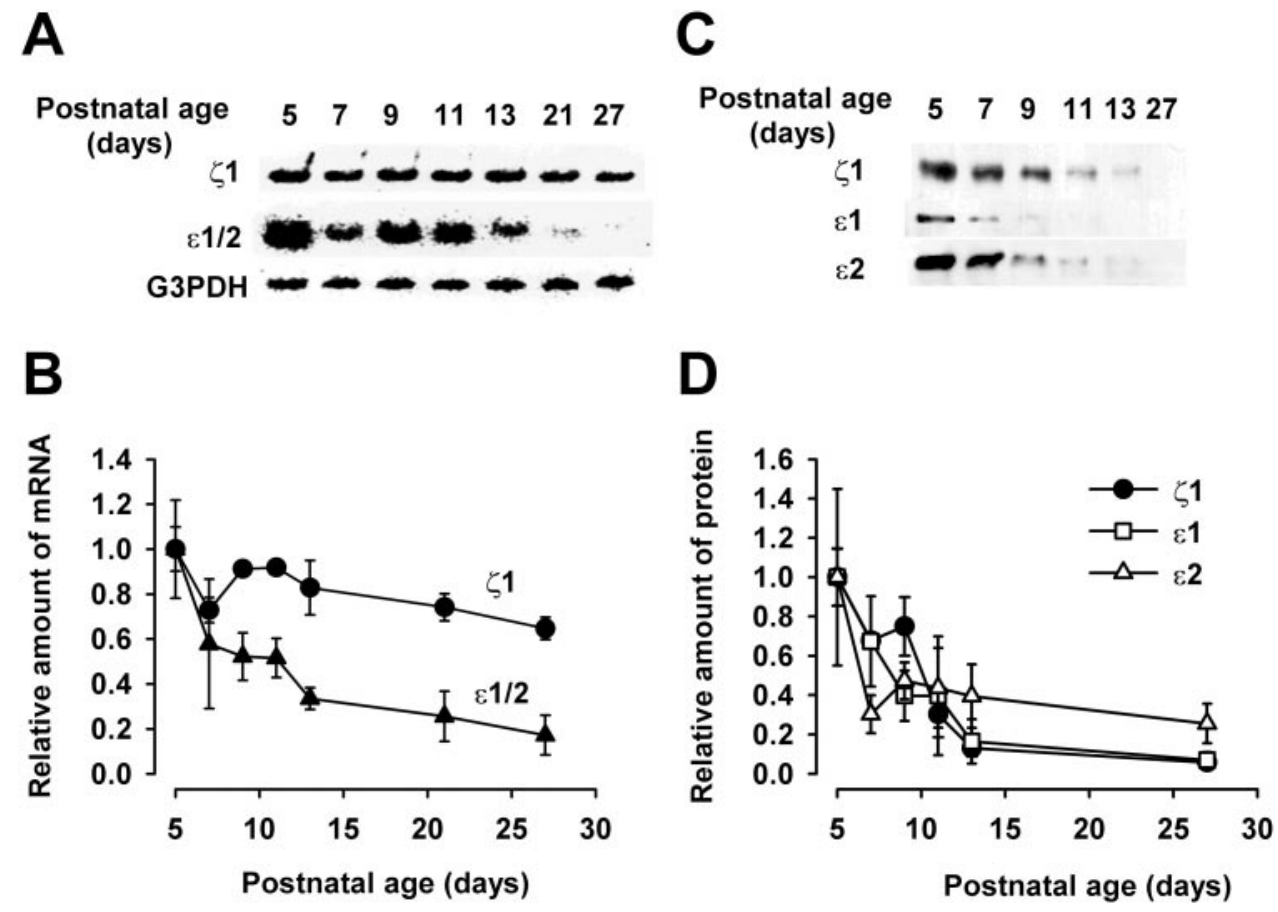

Figure 6. Developmental changes in the expression of NMDA receptor subunit mRNAs and proteins. $A$, mRNAs encoding $\zeta 1, \epsilon 1$ and $\epsilon 2$, and G3PDH were detected by RT-PCR, using primers specific for $\zeta 1$, common to $\epsilon 1$ and $\epsilon 2$, or specific for G3PDH. $B$, Relative amounts of mRNA encoding $\zeta 1(\bullet)$ and $\epsilon 1 / 2(\boldsymbol{\Delta})$ expressed at different postnatal days. Amounts of mRNA relative to G3PDH mRNA were measured and normalized to those at P5. Mean values were derived from three experiments. $C$, Immunoblots of $\zeta 1, \epsilon 1$, and $\epsilon 2$ subunit proteins at different postnatal days. $D$, Relative amounts of $\zeta 1(\bullet), \epsilon 1$ $(\square)$, and $\epsilon 2(\triangle)$ protein expressed at different postnatal days, deduced from immunoreactivity (from 3 experiments), and normalized to the values at P5. removing picrotoxin and strychnine from superfusates (at $35^{\circ} \mathrm{C}$; data not shown), suggesting that inhibitory inputs are not involved in the fidelity of transmission at this synapse.

\section{Developmental changes of NMDA-EPSCs and AMPA-EPSCs}

Given that NMDA receptors negatively contribute to the fidelity of transmission and that the high-fidelity transmission is acquired through development, we examined whether the amplitude of NMDA-EPSCs might decrease with development at this calyceal synapse. NMDA-EPSCs were recorded at a holding potential of $+51 \mathrm{mV}$ in the presence of the AMPA/kainate receptor antagonist CNQX $(20 \mu \mathrm{M})$, which blocked EPSCs almost completely at $-79 \mathrm{mV}$ (data not shown). The mean amplitude of NMDAEPSCs was large until P11 but diminished steeply thereafter (Fig. 4). As mice matured, NMDA-EPSCs became faster, particularly in their decay time kinetics, as reported at other synapses (Carmignoto and Vicini, 1992; Hestrin, 1992), partly because of the $\epsilon 2$-to- $\epsilon 1$ subunit switch (Takahashi et al., 1996; Flint et al., 1997; Cathala et al., 2000).

In contrast to NMDA-EPSCs, the mean amplitude of AMPAEPSCs increased with postnatal development (Fig. 5A), although AMPA-EPSCs in rats are reported to remain constant throughout development (Iwasaki and Takahashi, 2000; Taschenberger and Gersdorff, 2000). As mice matured, both the rise time (1090\%) and decay time constant of AMPA-EPSCs became faster (Fig. 5B). These changes occurred between P5 and P14 in mice, just as reported in rats (Taschenberger and Gersdorff, 2000), and reached minimal levels thereafter. The amplitude and kinetics of AMPA-EPSCs might be distorted if the voltage clamp of cells was inadequate, and these distortions must be greater for larger EPSCs in more mature animals. Thus the developmental changes in the amplitude and kinetics of AMPA-EPSCs might be even greater than they looked.

\section{Developmental changes in the expressions of mRNAs and proteins of NMDA receptor subunits}

We next examined developmental changes in the NMDA receptors in the MNTB region. Expressions of mRNAs encoding $\zeta 1$ (equivalent to $\mathrm{NR} 1$ in rat) and $\epsilon 1$ (NR2A) plus $\epsilon 2$ (NR2B) subunits in the MNTB region were measured at different postnatal days by using mRNA encoding the housekeeping enzyme G3PDH as a standard. Messenger RNAs encoding $\zeta 1$ subunits as well as those encoding $\epsilon 1 / 2$ subunits decreased with development, with the slope of decrease of the latter being steeper (Fig. 6A,B). Expressions of NMDA receptor subunit proteins also were examined by using antibodies specific to each subunit (Fig. 6C,D). Similar to the transcripts, $\zeta 1, \epsilon 1$, and $\epsilon 2$ subunit proteins decreased with development (Fig. 6C,D). These results suggest that the developmental decrease in the amplitude of NMDA-EPSCs is caused by the decrease in the expression of NMDA receptors rather than by their redistribution. A steeper decline of $\zeta 1$ protein compared with its transcript may suggest a post-transcriptional regulation of $\zeta 1$ subunit, as reported for cultured cell lines (Sucher et al., 1993; Boeckman and Aizenman, 1994).

\section{Activity-dependent downregulation of NMDA receptor expression}

Steep declines both in the amplitude of NMDA-EPSCs (see Fig. 4 ) and in the NMDA receptor expression (Fig. 6D) were observed during the second postnatal week when mice begin to detect sound (Mikaelian and Ruben, 1964; Kikuchi and Hilding, 1965). Using the auditory brainstem response (ABR) as an index, we examined when the mice of the strain used in the present experiments begin to detect sound (Fig. 7A). Until P9, no ABR was observed in response to a "click" of $85 \mathrm{~dB}$ in intensity $(n=$ 20 mice). At P10 20\% of mice showed positive ABR to the click. The percentage increased steeply with postnatal days, and at P13 all mice showed positive ABR. We then addressed the question of whether auditory activity might downregulate postsynaptic NMDA receptor expression by performing bilateral cochlear 

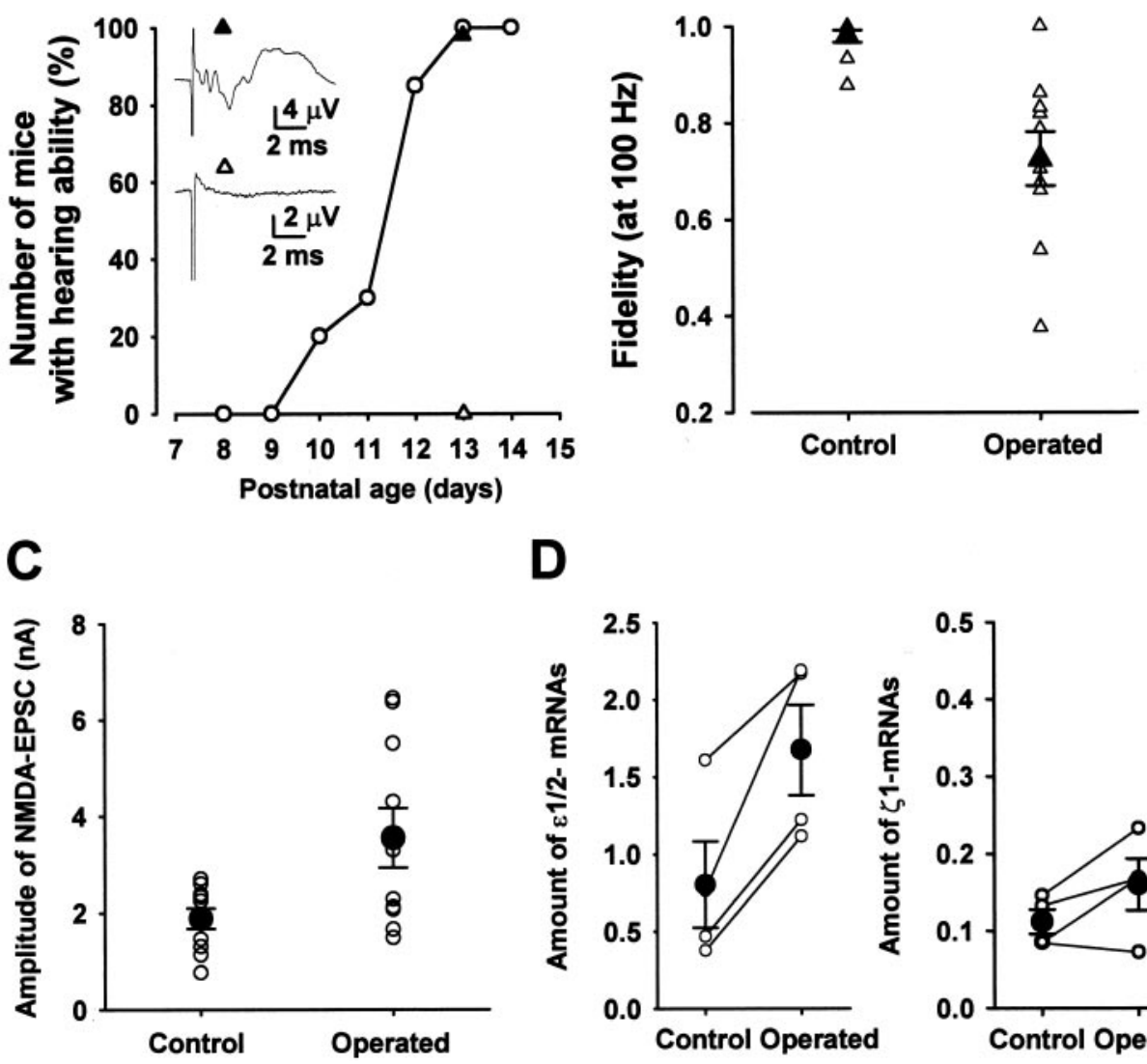

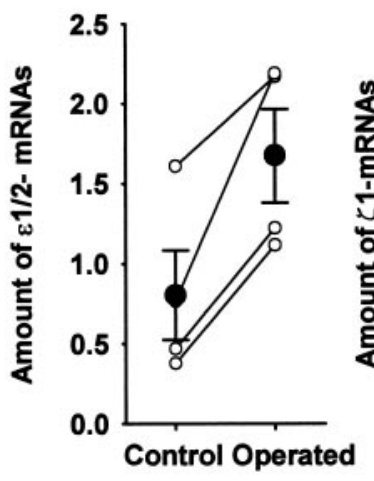

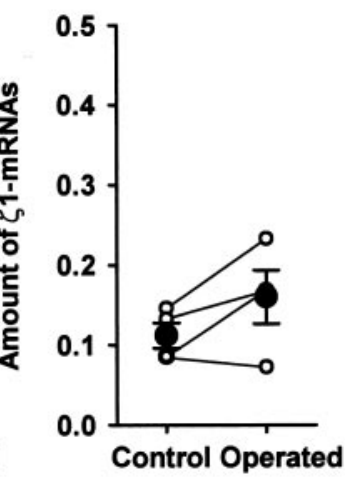

Figure 7. Effects of bilateral cochlear ablation on synaptic fidelity and NMDA receptor expression. $A$, Percentage of mice showing positive $\mathrm{ABR}$ to $85 \mathrm{~dB}$ clicks. Inset records are ABRs from sham-operated $(\mathbf{\Lambda})$ and operated P13 mice ( $\triangle$; bilateral cochlea ablated at P7) derived from the same litter. Numbers of untreated mice $(\bigcirc)$ were 10 for each period and 40 and 39 , respectively, for sham-operated and operated mice. $B$, Synaptic fidelity during $100 \mathrm{~Hz}$ stimulation in operated and sham-operated control mice at P14-P16 ( $n=10$ mice each). $C$, Mean amplitude of NMDA-EPSCs in P14-P16 mice $(n=10)$. $D$, Amounts of $\epsilon 1 / 2$ mRNA (left) and $\zeta 1$ mRNA (right) expressed in the MNTB region in sham-operated and operated mice at P14-P16. Ordinates indicate the amount of mRNA encoding NMDA receptor subunits relative to G3PDH mRNA. Data measured from the same experiments (using 5 mice each) are connected with lines (4 experiments). Difference was significant ( $p<0.02$, paired $t$ test) for $\epsilon 1 / 2$ mRNAs but was not significant for $\zeta 1$ mRNAs $(p>0.1)$. ablations in P7 mice. Bilateral ablation was preferred to unilateral ablation because the latter induces reorganization of the superior olivary complex (Russell and Moore, 1995). Successful cochlear ablation was confirmed at P13 by the absence of ABR to an $85 \mathrm{~dB}$ click (Fig. 7A). The ABR was normal in sham-operated mice. Whole-cell recordings were made from MNTB neurons in P14P16 mice with their hearing activity ablated (Fig. 7B). In such mice the fidelity of synaptic transmission during $100 \mathrm{~Hz}$ stimulation (ratio, $0.73 \pm 0.06 ; n=10$ ) was significantly lower than that of sham-operated controls $(0.98 \pm 0.001 ; n=10 ; p<0.01$, Welch's test). Also, in operated mice the mean amplitude of NMDA-EPSC $(3.6 \pm 0.6 \mathrm{nA} ; n=10)$ was significantly larger than that of sham-operated control mice $(1.9 \pm 0.2 \mathrm{nA} ; n=10 ; p<$ 0.05) (Fig. 7C). Furthermore, the expression of mRNAs encoding NMDA receptor $\epsilon 1 / 2$ subunits in the MNTB region was significantly higher in the mice with cochlear ablation than in shamoperated controls ( $p<0.02$, paired $t$ test), although the difference was not significant for the $\zeta$ subunit $(p>0.1$; Fig. $7 D)$. Taken together, these results suggest that auditory activity downregulates postsynaptic NMDA receptors, thereby contributing to the establishment of the high-fidelity transmission through postnatal development.

\section{DISCUSSION}

\section{Establishment of high-fidelity synaptic transmission at the calyx-MNTB synapse}

Mature principal neurons in the MNTB can follow inputs at frequencies as high as several hundred Hertz (Guinan and Li, 1990; Wu and Kelly, 1993) and above $500 \mathrm{~Hz}$ for a short train (Wu and Kelly, 1993; Taschenberger and von Gersdorff, 2000). In contrast, in immature mice the synaptic transmission in response to high-frequency inputs was inaccurate mainly because of the summed effect of large NMDA components in EPSPs, which triggered aberrant firings or blocked action potential generation. As animals matured, the expression of postsynaptic NMDA receptors decreased, thereby supporting the acquisition of highfidelity synaptic transmission. The developmental speeding in the kinetics of NMDA-EPSCs additionally may contribute to this functional maturation. Contrary to our results, it recently has been reported that D,L-APV $(50 \mu \mathrm{M})$ does not affect the number of action potentials generated during $100 \mathrm{~Hz}$ stimulation at the rat calyceal synapse in $\mathrm{P} 6$ rats at $21-23^{\circ} \mathrm{C}$ (Taschenberger and von Gersdorff, 2000). In addition to differences in species (rat vs mice) and postnatal days (P6 vs P7), our experiments were performed at higher temperature $\left(26-27^{\circ} \mathrm{C}\right)$ and with the NMDA receptor blocker at a concentration (D-APV, $50 \mu \mathrm{M}$ ) sufficient to block completely the NMDA-EPSPs in P7 mice. Thus EPSPs recorded in our experiments in the presence of the NMDA receptor blocker might be shorter than those recorded in rats, therefore resulting in higher synaptic fidelity.

After NMDA receptors were blocked, stimulation at frequencies higher than $200 \mathrm{~Hz}$ still caused aberrant firings in P7 mice, but not in P27 mice, suggesting that additional factors might be involved in the development of synaptic fidelity. One important factor may be the kinetics of AMPA-EPSCs, which undergo developmental speeding, thereby possibly reducing the sustained depolarization during high-frequency transmission. At the calyx of Held synapse, repetitive stimulation causes a synaptic depres- 
sion (von Gersdorff et al., 1997), and the magnitude of depression decreases as the animals mature (Iwasaki and Takahashi, 2000; Taschenberger and von Gersdorff, 2000). This additionally may contribute to the developmental acquisition of fidelity in transmission. Developmental changes in the voltage-dependent conductance and passive membrane properties of postsynaptic cells also may contribute to the maturation of high-fidelity transmission. It has been suggested that a high-threshold potassium conductance in MNTB neurons contributes to a high-fidelity transmission via rapid repolarization of action potentials (Brew and Forsythe, 1995). It remains to be seen whether the expression of this potassium conductance changes with postnatal development.

\section{Activity-dependent downregulation of NMDA receptors}

Mice begin to detect sound between P10 and P12, during which time the NMDA component of EPSCs rapidly decreases. Cochlear ablation before this critical period attenuated the developmental diminishment of NMDA-EPSCs and interfered with the acquisition of high-fidelity synaptic transmission. These results suggest that the developmental downregulation of postsynaptic NMDA receptors and resultant acquisition of high-fidelity synaptic transmission are dependent on acoustic activity, although other factors secondary to neuronal degeneration of afferent fibers might not be excluded from the present experiments. A steep decrease in the mean amplitude of NMDA-EPSCs was observed soon after the hearing onset. However, NMDA receptor subunit proteins in the MNTB regions begin to decrease earlier than this critical period, suggesting that there may be additional downregulatory mechanisms, particularly for the extrasynaptic NMDA receptors.

Similar to our results in mice auditory brainstem, the NMDA component of visual responses in the developing cat visual cortex decreases as the animals mature (Tsumoto et al., 1987; Fox et al., 1989). Also, this decrease is attenuated in dark-reared animals (Fox et al., 1991). In the developing rat visual cortex, however, the mean amplitude of NMDA-EPSCs does not change, although their decay time kinetics become faster with development in an activity-dependent manner (Carmignoto and Vicini, 1992). It has been suggested that the developmental decrease in the NMDA component of visual responses in cats might result from the acceleration of synaptic currents. In contrast, in the mice auditory brainstem the mean amplitude of NMDA-EPSCs did decrease with development, and cochlear ablation attenuated this de-

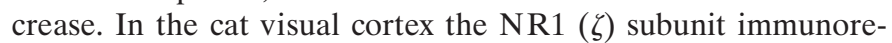
activity decreases with development, but this change is not attenuated by dark rearing (Catalano et al., 1997). In the mice auditory brainstem, cochlear ablations had no effect on $\zeta$ subunit mRNA but significantly attenuated the developmental decrease of $\epsilon$ subunit mRNA. The $\epsilon$ subunits in combination with the $\zeta$ subunit are essential for the activity of functional NMDA receptors (Meguro et al., 1992; Boeckman and Aizenman, 1994; Kutsuwada et al., 1996). Therefore, a developmental decrease in the $\epsilon$ subunit and attenuation of this decrease by cochlear ablations can explain the concomitant changes in the amplitude of NMDA-EPSCs.

During the early period of ontogeny NMDA receptors contribute to neuronal migration (Komuro and Rakic, 1993; Farrant et al., 1994) and functional synaptic formation (Durand et al., 1996). Thereafter, at the calyx of Held synapse, NMDA receptors undergo a developmental downregulation partly via auditory activity, thereby differentiating this synapse into the high-fidelity one that is suitable for the sound source localization.

\section{REFERENCES}

Boeckman FA, Aizenman E (1994) Stable transfection of the NR1 subunit in Chinese hamster ovary cells fails to produce a functional $N$-methyl-D-aspartate receptor. Neurosci Lett 173:189-192.

Brew HM, Forsythe ID (1995) Two voltage-dependent $\mathrm{K}^{+}$conductances with complementary functions in postsynaptic integration at a central auditory synapse. J Neurosci 15:8011-8022.

Carmignoto G, Vicini S (1992) Activity-dependent decrease in NMDA receptor responses during development of the visual cortex. Science 258:1007-1011.

Catalano SM, Chang CK, Shatz CJ (1997) Activity-dependent regulation of NMDAR1 immunoreactivity in the developing visual cortex. J Neurosci 17:8376-8390.

Cathala L, Misra C, Cull-Candy S (2000) Developmental profile of the changing properties of NMDA receptors at cerebellar mossy fibergranule cell synapses. J Neurosci 20:5899-5905.

Durand GM, Kovalchuk Y, Konnerth A (1996) Long-term potentiation and functional synapse induction in developing hippocampus. Nature 381:71-75.

Farrant M, Feldmeyer D, Takahashi T, Cull-Candy SG (1994) NMDA receptor channel diversity in the developing cerebellum. Nature 368:335-339.

Flint AC, Maisch US, Weishaupt JH, Kriegstein AR, Monyer H (1997) NR2A subunit expression shortens NMDA receptor synaptic currents in developing neocortex. J Neurosci 17:2469-2476.

Forsythe ID, Barnes-Davies M (1993) The binaural auditory pathway: membrane currents limiting multiple action potential generation in the rat medial nucleus of the trapezoid body. Proc R Soc Lond [Biol] 251:143-150.

Fox K, Sato H, Daw N (1989) The location and function of NMDA receptors in cat and kitten visual cortex. J Neurosci 9:2443-2454.

Fox K, Daw N, Sato H, Czepita D (1991) Dark-rearing delays the loss of NMDA-receptor function in kitten visual cortex. Nature 350:342-344.

Guinan Jr JJ, Li RY-S (1990) Signal processing in brainstem auditory neurons which receive giant endings (calyces of Held) in the medial nucleus of the trapezoid body of the cat. Hear Res 49:321-334.

Held H (1893) Die centrale Gehörleitung. Arch Anat Physiol Anat Abt 17:201-248

Hestrin S (1992) Developmental regulation of NMDA receptormediated synaptic currents at a central synapse. Nature 357:686-689.

Iwasaki S, Takahashi T (1998) Developmental changes in calcium channel types mediating synaptic transmission in rat auditory brainstem. J Physiol (Lond) 509:419-423.

Iwasaki S, Takahashi T (2000) Developmental changes in synaptic efficacy at the medial nucleus of trapezoid body in rats. Jpn J Physiol (Lond) Suppl 50:S135.

Kandler K, Friauf E (1993) Pre- and postnatal development of efferent connections of the cochlear nucleus in the rat. J Comp Neurol 328:161-184.

Kikuchi K, Hilding D (1965) The development of the organ of Corti in the mouse. Acta Otolaryngol 60:207-222.

Komuro H, Rakic P (1993) Modulation of neuronal migration by NMDA receptors. Science 260:95-97.

Kutsuwada T, Sakimura K, Manabe T, Takayama C, Katakura N, Kushiya E, Natsume R, Watanabe M, Inoue Y, Yagi T, Aizawa S, Arakawa M, Takahashi T, Nakamura Y, Mori H, Mishina M (1996) Impairment of suckling response, trigeminal neuronal pattern formation, and hippocampal LTD in NMDA receptor $\epsilon 2$ subunit mutant mice. Neuron 16:333-344.

Meguro H, Mori H, Araki K, Kushiya E, Kutsuwada T, Yamazaki M, Kumanishi T, Arakawa M, Sakimura K, Mishina M (1992) Functional characterization of a heteromeric NMDA receptor channel expressed from cloned cDNAs. Nature 357:70-74.

Mikaelian D, Ruben RJ (1964) Development of hearing in the normal CBA-J mouse. Acta Otolaryngol 59:451-461.

Mizuta I, Katayama M, Watanabe M, Mishina M, Ishii K (1998) Developmental expression of NMDA receptor subunits and the emergence of glutamate neurotoxicity in primary cultures of murine cerebral cortical neurons. Cell Mol Life Sci 54:721-725.

Oertel D (1997) Encoding of timing in the brain stem auditory nuclei of vertebrates. Neuron 19:959-962.

Russell FA, Moore DR (1995) Afferent reorganization within the superior olivary complex of the gerbil: development and induction by neonatal, unilateral cochlear removal. J Comp Neurol 352:607-625.

Sakaguchi T, Okada M, Kuno M, Kawasaki K (1997) Dual mode of $N$-methyl-D-aspartate-induced neuronal death in hippocampal slice cultures in relation to $N$-methyl-D-aspartate receptor properties. Neuroscience 76:411-423.

Sucher NJ, Brose N, Deitcher DL, Awobuluyi M, Gasic GP, Bading H, Cepko CL, Greenberg ME, Jahn R, Heinemann SF, Lipton SA (1993) 
Expression of endogenous NMDAR1 transcripts without receptor protein suggests post-transcriptional control in PC12 cells. J Biol Chem 268:22299-22304.

Takahashi T, Feldmeyer D, Suzuki N, Onodera K, Cull-Candy SG, Sakimura K, Mishina M (1996) Functional correlation of NMDA' receptor $\epsilon$ subunits expression with the properties of single-channel and synaptic currents in the developing cerebellum. J Neurosci 16:4376-4382.

Taschenberger H, von Gersdorff H (2000) Fine-tuning an auditory synapse for speed and fidelity: developmental changes in presynaptic waveform, EPSC kinetics, and synaptic plasticity. J Neurosci 20:9162-9173.
Trussell LO (1997) Cellular mechanisms for preservation of timing in central auditory pathways. Curr Opin Neurobiol 7:487-492.

Tsumoto T, Hagihara K, Sato H, Hata Y (1987) NMDA receptors in the visual cortex of young kittens are more effective than those of adult cats. Nature 327:513-514.

von Gersdorff H, Schneggenburger R, Weis S, Neher E (1997) Presynaptic depression at a calyx synapse: the small contribution of metabotropic glutamate receptors. J Neurosci 17:8137-8146.

Wu SH, Kelly JB (1993) Response of neurons in the lateral superior olive and medial nucleus of the trapezoid body to repetitive stimulation: intracellular and extracellular recordings from mouse brain slice. Hear Res 68:189-201. 